\title{
Rule Based System for Medicine Inventory Control Using Radio Frequency Identification (RFID)
}

\author{
Joanna Ardhyanti Mita Nugraha ${ }^{1, *}$, Suryono Suryono ${ }^{1,2}$, dan Jatmiko Endro Suseno ${ }^{2}$ \\ ${ }^{1}$ Magister of Information System, Diponegoro University, Semarang - Indonesia \\ ${ }^{2}$ Physics Department of Science and Mathematics Faculty, Diponegoro University, Semarang - Indonesia
}

\begin{abstract}
Rule based system is very efficient to ensure stock of drug to remain available by utilizing Radio Frequency Identification (RFID) as input means automatically. This method can ensure the stock of drugs to remain available by analyzing the needs of drug users. The research data was the amount of drug usage in hospital for 1 year. The data was processed by using $\mathrm{ABC}$ classification to determine the drug with fast, medium and slow movement. In each classification result, rule based algorithm was given for determination of safety stock and Reorder Point (ROP). This research yielded safety stock and ROP values that vary depending on the class of each drug. Validation is done by comparing the calculation of safety stock and reorder point both manually and by system, then, it was found that the mean deviation value at safety stock was 0,03 and and ROP was 0,08 .
\end{abstract}

\section{Introduction}

Rule based system uses explicit knowledge and provide certain flexibility in terms of altering knowledge taken [1]. It was once used in ship design research and was able to create principles for machine layout architecture by concerning the relationship among equipment and ship-owner needs, insight, design, etc. In addition, rule based system that has been developed become more common and can be applied to a wider product [1], [2].

Rule based system is highly efficient and achieves an accuracy of up to $94.29 \%$ in research aiming at estimating tomato ripeness based on the color. The set of rules is generated automatically from a set of derived features using a decision tree. Expert knowledge is quickly converted into computer programs in the form of if-then-rules. Moreover, expert knowledge also reduces the search space while optimizing the system [3].

The use of instructions is needed in the pharmaceutical world, for example in the field of drug supply, which is the most important factor in the process of health care. Poor management of drugs will result in stagnant drug stocks (excess supply of medicines) and stockout (deficiency or void of drug supply). Stagnant drug supplies have risks in expiration and damage if they are not stored properly. The stagnant and stockout drugs will have an impact on health cares [4].

In inventory systems, the use of RFID technology is believed to have a major impact on revenue increase [5], such as in clothing retail industries, health industries, education, etc. The application of RFID technology used in healthcare apparel management research can also save up to $30 \%$ of total cloth spending. In addition, RFID has also been used in research to ensure that patients' beds and mattresses can be cleaned properly with efficient time and cost, and can shorten work time [5], [6].

Hospital is a health service institution that provides inpatient, outpatient and emergency care services. Hospitals together with their sub-organizations must be managed as well as possible in order to provide health services as much as possible. Pharmacy service is a supporting service and also a main revenue center. This is because more than $90 \%$ of health services in hospitals use pharmaceutical supplies, such as medicines, chemicals, medical devices, medical devices and medical gases [7].

The management of drugs in hospitals is routine, urgent and periodic activities which means they must always be available and should not be void. In other words, stockout can disrupt the operational activities of the hospital. In addition, the drug stockout may result in a loss of having to order and immediately deliver medication with higher price than buying from a supplier [7].

Some previously unknown information or knowledge can be found from the data. The data has the potential as supporting evidence to reflect some important patterns by using modeling techniques. Moreover, the model can be revised automatically because the database can be updated in real time when modeling techniques are used. Data can be represented as a rule. Basic rules can be used to manage regulations effectively and efficiently by noticing storage and retrieval. The most commonly used method for representing rules is the rule based system

* Corresponding author: joanna.nugraha@gmail.com 
[8]. Always Better Control (ABC) analysis is one way of controlling inventory by sorting and classifying the type of goods. Research in India used ABC analysis and Vital Esensial Non-esensial (VEN) analysis for efficient drug management. The results obtained from ABC-VEN matrix analysis showed that only $21 \%$ of 1536 stock items of drugs belonging to class A require maximum attention [9].

From the above explanation, the rule-based system is very efficient and can help in the process of controlling the inventory system by combining $\mathrm{ABC}$ analysis in it. In addition, RFID is capable of performing the process of reading data automatically that can be used for the identification process of drug data. Therefore this research will apply rule-based system method to know safety stock of drug supplies using RFID input system.

\section{Methods}

Research has several stages to obtain maximum results, including use-value analysis using $\mathrm{ABC}$ classification, Safety Stock (SS) and Reorder Point (ROP) calculations, drug supply system analysis and drug supply system implementation.

\subsection{Analysis of use-value by $A B C$ classification}

The $\mathrm{ABC}$ classification is performed by the analysis of drug use-value. The drug use-value is obtained from the amount of usage in one period, then sorted from the highest usage amount to the lowest usage amount. After the item data is sorted, the percentage of usage, then, is calculated with the following calculation [7].

$$
\text { Percentage of usage : }\left(\frac{x}{\Sigma x}\right) \times 100 \% \text { (1) }
$$

From the above formula, it is known that $\mathrm{x}$ is the amount of usage per item of drug and $\Sigma \mathrm{x}$ is the total amount of drug usage. After the percentage of usage is calculated, the categories of preparations are made in accordance with the cumulative percentage of $70 \%$, $20 \%$, and $10 \%$ [20]. The steps used in the $\mathrm{ABC}$ classification are:

a. Counting the number of monthly usage in 2016 for each item.

b. Sorting usage values, ranging from the largest to the smallest, then a percentage of the value of usage is made.

c. Finding the cumulative value of usage by summing the value of the percentage of usage that has been ranked. Group A with a percentage of $70 \%$, group B with a percentage of $20 \%$ and group $\mathrm{C}$ with a percentage of $10 \%$.

\subsection{Calculation of Safety Stock (SS) and Reorder Point (ROP)}

The importance of calculating safety stocks due to frequent new orders after the lead time is too late (e.g. late travel due to traffic jams or hit by a disaster) and the frequent increase in production demand. This situation will result in the stock out which will further decrease the level of service at hospitals. Due to the amount of investment for safety stock inventory especially for the most frequently used drugs (class A) then safety stock is prioritized to vital medicines. The way to calculate the amount of safety stock by using VEN system guidance is shown in Table 2.1. [7]

Tabel 2.1 Determination of safety stock using VEN guideline

\begin{tabular}{|c|c|}
\hline Groups of VEN & Safe ty Stock \\
\hline Vital & $20 \%$ of last usage \\
\hline Essential & $10 \%$ of last usage \\
\hline Non essential & $5 \%$ of last usage \\
\hline
\end{tabular}

Factors affecting ROP are lead time, average usage and safety stock, can be calculated by the formula [10]:

$$
\mathrm{ROP}=(\mathrm{LT} \times \mathrm{d})+\mathrm{SS}
$$

With ROP as the reorder point, LT is the lead time which is the time required when the drug is ordered until the drug arrives at hospital. Then $d$ is the average usage in a given period of time. And SS is safety stock which is an additional supply to protect and preserve the possibility of material deficiency [10].

\subsection{Analysis of drug supply system}

A shortage and excess supply of drugs commonly happen in hospitals. This is caused by supply planning that does not suit the patients' needs. By applying rulebased system method, drug supply planning is made based on the needs of patients.

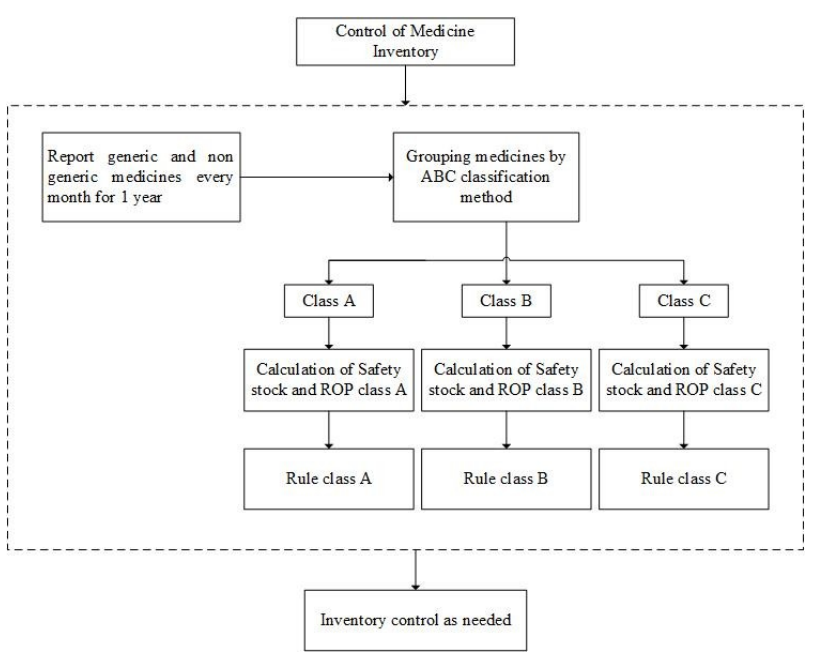

Fig. 1. Theoretical framework

The data used are reports of drug use which will be processed using $\mathrm{ABC}$ classification and rule based system method. RFID technology serves to accelerate the process of input and output data and avoid errors. RFID is used to scan every incoming and used drug, so the 
officers do not need to enter the drug data to accelerate the process of drug entry. There are two users involved in the system, in the warehouse and hospital pharmacy. The description of the research flow lies in the theoretical framework as shown in Figure 1.

\subsection{Implementation of drug supply system}

The result of data analysis using $\mathrm{ABC}$ classification is fast, moderate and slow moving drugs. After classification is done, next is to apply rule based system method to know safety stock and ROP from each type of drug based on fast moving, moderate and slow moving drug classification. The procedures for performing decision tree analysis are:

1. Identifying all decision points and other possibilities that will occur

2. Identifying decision alternatives for each decision point

3. Identifying what might happen from every decision

4. Creating a tree diagram showing the order of decisions and events that may occur

And the rule based will be shown with the decision tree in Figure 2.

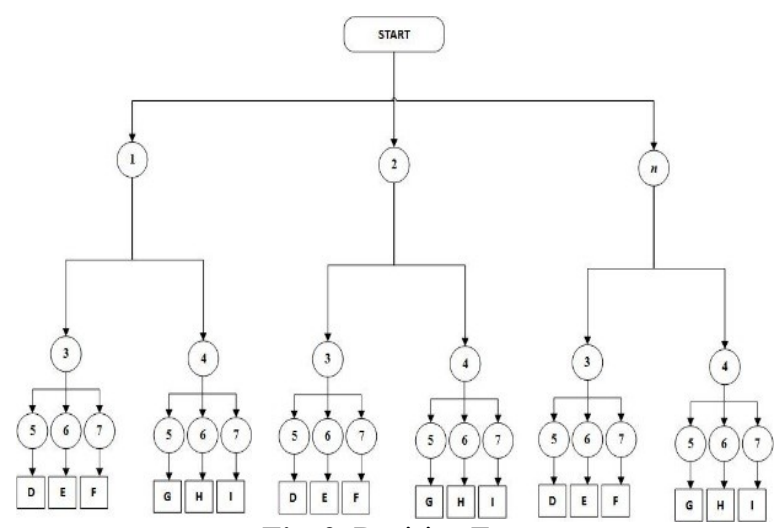

Fig. 2. Decision Tree

In the decision tree, it shows number 1 , number 2 to $\mathrm{n}$, where $\mathrm{n}=12$ which is the number of months of the year. Then number 3 is a generic drug and number 4 is a non generic drug. Then number 5 is the classification of fast moving drugs, number 6 is the classification of moderate drugs and number 7 is the classification of slow moving drugs. And D is the rule for fast moving drug classification, $\mathrm{E}$ is the rule for moderate drug classification and $\mathrm{F}$ is the rule for the classification of slow moving drugs. The rule description of the decision tree will be shown in Table 1 .
Table 1. Explanation of rule of decision tree

\begin{tabular}{|c|l|}
\hline Alphabet & \multicolumn{1}{|c|}{ Rule } \\
\hline D & $\begin{array}{l}\text { IF Medicine out of January AND generic medicine AND fast } \\
\text { moving THEN safety stock 20\% of last usage }\end{array}$ \\
\hline E & $\begin{array}{l}\text { IF Medicine out of January AND generic medicine AND } \\
\text { moderate THEN safety stock 10\% of last usage }\end{array}$ \\
\hline F & $\begin{array}{l}\text { IF Medicine out of January AND generic medicine AND slow } \\
\text { moving THEN safety stock 5\% of last usage }\end{array}$ \\
\hline G & $\begin{array}{l}\text { IF Medicine out of January AND non-generic medicine AND } \\
\text { fast moving THEN safety stock 20\% of last usage }\end{array}$ \\
\hline H & $\begin{array}{l}\text { IF Medicine out of January AND non-generic medicine AND } \\
\text { fast moving THEN safety stock 10\% of last usage }\end{array}$ \\
\hline I & $\begin{array}{l}\text { IF Medicine out of January AND non-generic medicine AND } \\
\text { fast moving THEN safety stock 5\% of last usage }\end{array}$ \\
\hline
\end{tabular}

\section{Results and Discussion}

\subsection{Calculation process of $A B C$ classification}

To calculate $\mathrm{ABC}$ classification based on use-value, the steps are as follows:

a. Calculating the monthly usage amount in 2016 for each drug item by using formula (1) as shown in Table 2.

Table 2. The calculation of the amount of usage

\begin{tabular}{|c|l|l|c|c|}
\hline NO & \multicolumn{1}{|c|}{ MEDICINE NAME } & VALUE & $\begin{array}{c}\text { AMOUNT } \\
\text { USAGE }\end{array}$ & $\begin{array}{c}\text { AMOUNT } \\
\text { USAGE } \\
(\%)\end{array}$ \\
\hline 1 & ASAM MEFENAMAT TAB 500 MG & TABLET & 2370 & $6,34 \%$ \\
\hline 2 & METFORMIN TAB 500 MG & TABLET & 2283 & $6,11 \%$ \\
\hline 3 & PARACETAMOL TAB 500 MG & TABLET & 2071 & $5,54 \%$ \\
\hline 4 & RINGER LAKTAT LAR INF 500 ML & PLABOT & 1913 & $5,12 \%$ \\
\hline 5 & VITAMIN B COMPLEX & TABLET & 1299 & $3,48 \%$ \\
\hline 6 & OMEPRAZOL KAP 20 MG & CAPSULE & 1102 & $2,95 \%$ \\
\hline 7 & RANITIDIN TAB 150 MG & TABLET & 1031 & $2,76 \%$ \\
\hline 8 & CEFADROXIL KAP 500 MG & CAPSULE & 943 & $2,52 \%$ \\
\hline 9 & VITAMIN C 50 MG TAB & TABLET & 834 & $2,23 \%$ \\
\hline 10 & CIPROFLOXACIN TAB 500 MG & TABLET & 795 & $2,13 \%$ \\
\hline & & & $\ldots$ & \\
\hline 196 & SALEP KULIT BASITRASIN 500 IU/G & TUBE & 1 & $0,00 \%$ \\
\hline & \multicolumn{1}{|c}{ TOTAL } & & $\mathbf{3 7 3 5 3}$ & \\
\hline
\end{tabular}

b. Sorting usage values, ranging from the largest to the smallest, then a percentage of usage values is made as shown in Table 3 .

c. Finding the cumulative value of usage by summing the value of the percentage of usage that has been ranked. Class A with a percentage of $70 \%$, class B with a percentage of $20 \%$ and class $C$ with a percentage of $10 \%$.

So from the classification of $\mathrm{ABC}$, the drugs in class A include the vital group with the calculation of safety stock of $20 \%$ of the past use, class B includes the essential group with the calculation of safety stock of $10 \%$ of past use and class $\mathrm{C}$ includes non-essential group with the calculation Safety stock of $5 \%$ of the usage then shown in Table 3. For ROP calculation has been determined by the formula according to the average monthly usage and safety stock in each class, as shown in Table 4. 
Table 3. Result of safety stock calculation in each class

\begin{tabular}{|c|l|l|c|c|c|c|}
\hline NO & \multicolumn{1}{|c|}{ MEDICINE NAME } & VALUE & $\begin{array}{c}\text { AMOUNT } \\
\text { USAGE }\end{array}$ & $\begin{array}{c}\text { AMOUNT } \\
\text { USAGE } \\
(\%)\end{array}$ & CLASS & SS \\
\hline 1 & ASAM MEFENAMAT TAB 500 MG & TABLET & 2370 & $6,34 \%$ & A & 474 \\
\hline 2 & METFORMIN TAB 500 MG & TABLET & 2283 & $6,11 \%$ & A & 457 \\
\hline 3 & PARACETAMOL TAB 500 MG & TABLET & 2071 & $5,54 \%$ & A & 414 \\
\hline 4 & RINGER LAKTAT LAR INF 500 ML & PLABOT & 1913 & $5,12 \%$ & A & 383 \\
\hline 5 & DIAZEPAM 2 MG TABLET & TABLET & 310 & $0,83 \%$ & B & 31 \\
\hline 6 & CEFTRIAXON 1 GR INJEKSI & VIAL & 308 & $0,82 \%$ & B & 31 \\
\hline 7 & ONDANSETRON INJ 4 MG/2 ML & AMPUL & 297 & $0,80 \%$ & B & 30 \\
\hline 8 & LOPERAMID TAB 2 MG & TABLET & 94 & $0,25 \%$ & C & 5 \\
\hline 9 & LSINOPRIL TAB 10 MG & TABLET & 90 & $0,24 \%$ & $\mathrm{C}$ & 5 \\
\hline 10 & PAPAVERIN TAB & TABLET & 90 & $0,24 \%$ & $\mathrm{C}$ & 5 \\
\hline
\end{tabular}

Table 4. Result of ROP calculation in each class

\begin{tabular}{|c|l|l|c|c|c|c|c|c|}
\hline NO & \multicolumn{1}{|c|}{ MEDICINE NAME } & VALUE & $\begin{array}{c}\text { AMOUNT } \\
\text { USAGE }\end{array}$ & $\begin{array}{c}\text { AMOUNT } \\
\text { USAGE } \\
(\%)\end{array}$ & CLASS & SS & d & ROP \\
\hline 1 & ASAM MEFENAMAT TAB 500 MG & TABLET & 2370 & $6,34 \%$ & A & 474 & 79 & 632 \\
\hline 2 & MEtFORMIN TAB 500 MG & TABLET & 2283 & $6,11 \%$ & A & 457 & 76 & 609 \\
\hline 3 & PARACETAMOL TAB 500 MG & TABLET & 2071 & $5,54 \%$ & A & 414 & 69 & 552 \\
\hline 4 & RINGER LAKTAT LAR INF 500 ML & PLABOT & 1913 & $5,12 \%$ & A & 383 & 64 & 510 \\
\hline 5 & DIAZEPAM 2 MG TABLET & TABLET & 310 & $0,83 \%$ & B & 31 & 10 & 52 \\
\hline 6 & CEFTRIAXON1 GR INEKSI & VIAL & 308 & $0,82 \%$ & B & 31 & 10 & 51 \\
\hline 7 & ONDANSETRON IN 4 MG/2 ML & AMPUL & 297 & $0,80 \%$ & B & 30 & 10 & 50 \\
\hline 8 & LOPERAMID TAB 2 MG & TABLET & 94 & $0,25 \%$ & C & 5 & 3 & 11 \\
\hline 9 & LSINOPRIL TAB 10 MG & TABLET & 90 & $0,24 \%$ & C & 5 & 3 & 11 \\
\hline 10 & PAPAVERIN TAB & TABLET & 90 & $0,24 \%$ & $\mathrm{C}$ & 5 & 3 & 11 \\
\hline
\end{tabular}

\subsection{Evaluation and validation of calculation result}

Verification is done by comparing manual calculations to perform $\mathrm{ABC}$ classification with calculation result using system. The data used for verification are 20 random data of generic drug types taken from each class, as shown in Table 5 .

Table 5. Verification result of $\mathrm{ABC}$ classification

\begin{tabular}{|c|c|c|c|c|c|c|c|c|}
\hline \multirow[t]{2}{*}{ No } & \multirow[t]{2}{*}{ MEDICINE NAME } & \multicolumn{3}{|c|}{$\begin{array}{l}\text { Calculation Result of ABC Manual } \\
\text { Classification }\end{array}$} & \multicolumn{3}{|c|}{$\begin{array}{l}\text { Calculation Result of ABC } \\
\text { Classification Using System }\end{array}$} & \multirow[t]{2}{*}{ Conformity } \\
\hline & & Fast Moving & \begin{tabular}{|l|l|}
$g$ & Moderate \\
\end{tabular} & Slow Moving & Fast Moving & Moderate & e Slow Moving & \\
\hline 1 & 2 & 3 & 4 & 5 & 6 & 7 & 8 & 9 \\
\hline 1 & AMOXICILIIN TAB $500 \mathrm{MG}$ & $\sqrt{1}$ & & & $\sqrt{ }$ & & & CORRESPONDING \\
\hline 2 & $\begin{array}{l}\text { RINGER LAKTAT LAR INF } 500 \mathrm{ML} \\
\end{array}$ & $\sqrt{ }$ & & & $\sqrt{ }$ & & & CORRESPONDING \\
\hline 3 & RANITIIN TAB 150 MG & $\sqrt{ }$ & & & $\sqrt{ }$ & & & CORRESPONDING \\
\hline 4 & FUROSEMID TAB 40 MG & & 1 & & & $\sqrt{1}$ & & CORRESPONDING \\
\hline 5 & RAMIPRIL TAB 10 MG & & & $\sqrt{ }$ & & & $\sqrt{1}$ & CORRESPONDING \\
\hline 6 & AMLODIPIN TAB 5 MG & V & & & V & & & CORRESPONDING \\
\hline 7 & \begin{tabular}{|l|l|} 
IBUPROFEN TAB $400 \mathrm{MG}$ \\
\end{tabular} & v & & & v & & & CORRESPONDING \\
\hline 8 & ASAM TRANEKSAMAT TAB $500 \mathrm{mg}$ & & 1 & & & 1 & & CORRESPONDING \\
\hline 9 & COTRIMOXAZOLE TAB 480 MG & & $\sqrt{ }$ & & & V & & CORRESPONDING \\
\hline 10 & ASAM FOLAT 1 MG TAB & & $\sqrt{1}$ & & & 1 & & CORRESPONDING \\
\hline 11 & ANTASIDA DOEN TAB & & $\sqrt{1}$ & & & $\sqrt{ }$ & & CORRESPONDING \\
\hline 12 & CIPROFLOXACIN INF 2 MG/ML & & & $\sqrt{ }$ & & & $\sqrt{ }$ & CORRESPONDING \\
\hline 13 & PROPANOLOL TAB 40 MG & & & $\sqrt{ }$ & & & $\sqrt{ }$ & CORRESPONDING \\
\hline 14 & CO-AMOXICLAV 625 MG & & & $\sqrt{1}$ & & & V & CORRESPONDING \\
\hline 15 & BETAHISTIN TAB & $\sqrt{ }$ & & & v & & & CORRESPONDING \\
\hline 16 & CEFIXIME KAP $100 \mathrm{MG}$ & $\sqrt{ }$ & & & $\sqrt{ }$ & & & CORRESPONDING \\
\hline 17 & AMITRIPTILIN TAB 25 MG & & & $\sqrt{ }$ & & & $\sqrt{ }$ & CORRESPONDING \\
\hline 18 & OMEPRAZOL IN 40 MG / VIAL & & & $\sqrt{1}$ & & & $\sqrt{ }$ & CORRESPONDING \\
\hline 19 & FLUNARIZIN TAB 5 MG & & & $\sqrt{1}$ & & & $\sqrt{1}$ & CORRESPONDING \\
\hline 20 & CIPROFLOXACIN TAB 500 MG & $\sqrt{v}$ & & & $\sqrt{ }$ & & & CORRESPONDING \\
\hline
\end{tabular}

Next, verification for safety stock and ROP calculation is performed. The verification is done by using the mean deviation formula by calculating the difference between system calculation and manual calculation, then searching for the average of data difference and dividing the amount of data used to perform the verification. The verification results show that the average deviation generated for the safety stock is 0.03 and for the ROP is 0.08 as shown in Table 6 .
Table 6. Verification of safety stock and ROP calculation

\begin{tabular}{|c|c|c|c|c|c|c|c|}
\hline \multirow[t]{2}{*}{ No } & \multirow[t]{2}{*}{ MEDICINE NAME } & \multicolumn{2}{|c|}{$\begin{array}{l}\text { Manual ABC Classification } \\
\text { Calculation Result }\end{array}$} & \multicolumn{2}{|c|}{$\begin{array}{l}\text { Calculation Result of ABC } \\
\text { Classification Using System }\end{array}$} & \multicolumn{2}{|c|}{ Difference } \\
\hline & & Safety Stock & ROP & Safety Stock & ROP & Safety Stok & ROP \\
\hline 1 & 2 & 3 & 4 & 5 & 6 & \begin{tabular}{|l|}
7 \\
\end{tabular} & 8 \\
\hline 1 & AMOXICILLIN TAB 500 MG & 106 & 142 & 107 & 143 & 1 & 1 \\
\hline 2 & RINGER LAKTAT LAR INF $500 \mathrm{ML}$ & 383 & 510 & 383 & 511 & 0 & 1 \\
\hline 3 & RANITIDIN TAB 150 MG & 206 & 275 & 207 & 277 & 1 & 2 \\
\hline 4 & FUROSEMID TAB 40 MG & 15 & 26 & 16 & 28 & 1 & 2 \\
\hline 5 & RAMIPRIL TAB $10 \mathrm{MG}$ & 2 & 4 & 2 & 4 & 1 & 1 \\
\hline 6 & AMLODIPIN TAB 5 MG & 101 & 134 & 101 & 135 & 0 & 1 \\
\hline 7 & |BUPROFEN TAB $400 \mathrm{MG}$ & 92 & 123 & 93 & 125 & 1 & 2 \\
\hline 8 & ASAM TRANEKSAMAT TAB $500 \mathrm{~m}$ & 23 & 39 & 24 & 40 & 1 & 1 \\
\hline 9 & COTRIMOXAZOLE TAB 480 MG & 16 & 26 & 16 & 28 & 0 & 2 \\
\hline 10 & ASAM FOLAT 1 MG TAB & 15 & 26 & 16 & 28 & 1 & 3 \\
\hline 11 & ANTASIDA DOEN TAB & 13 & 22 & 13 & 23 & 0 & 1 \\
\hline 12 & CIPROFLOXACIN INF 2 MG/ML & 5 & 11 & 4 & 10 & 1 & 1 \\
\hline 13 & \begin{tabular}{|l|} 
PROPANOLOL TAB $40 \mathrm{MG}$ \\
\end{tabular} & 5 & 11 & 4 & 10 & 1 & 1 \\
\hline 14 & CO-AMOXICLAV 625 MG & 4 & 10 & 4 & 10 & 0 & 0 \\
\hline 15 & BETAHISTIN TAB & 71 & 95 & 72 & 96 & 1 & 1 \\
\hline 16 & CEFIIIME KAP 100 MG & 85 & 113 & 85 & 115 & 0 & 2 \\
\hline 17 & \begin{tabular}{|l|l|} 
AMITRIPTILIN TAB 25 MG \\
\end{tabular} & 4 & 9 & 4 & 10 & 0 & 1 \\
\hline 18 & OMEPRAZOL INJ 40 MG / VIAL & 4 & 8 & 4 & 10 & 0 & 2 \\
\hline 19 & FLUNARIZIN TAB 5 MG & 3 & 7 & 4 & 10 & 1 & 3 \\
\hline \multirow[t]{2}{*}{20} & CIPROFLOXACIN TAB $500 \mathrm{MG}$ & 159 & 212 & 159 & 213 & 0 & 1 \\
\hline & & & & & $\begin{array}{l}\text { AVERAGE } \\
\text { DEVIATION }\end{array}$ & 0,03 & 0,08 \\
\hline
\end{tabular}

\section{Conclusions}

The supply control system can identify drugs with fast, moderate and slow movements by applying the $\mathrm{ABC}$ classification method. From the results of experiments in this study, ABC classification generated from the system has been in accordance with the results of manual $\mathrm{ABC}$ classification calculation. The rule-based system method can be applied to know safety stock and ROP on each drug based on its class. This is evident from the test results indicating that the average deviation produced is relatively small, i.e. for safety stock with an average deviation of 0.03 and for ROP with an average deviation of 0.08 .

\section{References}

1. C. A. Costa, M. A. Luciano, C. P. Lima, and R. I. Young, Advanced Engineering Informatics, 292305 (2012)

2. K.-S. Kim, M.-1. Roh, and S. Ha, Expert Systems With Applications, 1-14 (2015)

3. N. Goel, and P. Sehgal, Applied Soft Computing, 45-56 (2015)

4. F. A. Rosmania, and S. Supriyanto, Jurnal Administrasi Kesehatan Indonesia, (2015)

5. S. Suryono, J.E.Suseno, C.Mashuri, A.D.Sabila, J.A.M.Nugraha, M.H.Primasiwi, RFID Sensor for Automated Prediction of Reorder Point (ROP) values in a Vendor Management Inventory (VMI) System Using Fuzzy Times Series 23, 2398-2400 (2017)

6. H.-L. Chan, T.-M. Choi, and C.-L. Hui, Decision Support Systems, 803-811 (2012)

7. A. Ramadhan, Jurlan Ilmiah Komputer dan Informatika (KOMPUTA), 1-12 (2013) 
8. H. Liu, A. Gegov, and M. Cocea, Rule Based Systems for Big Data. London: Springer International Publishing Switzerland (2016)

9. M. S. Kumar, and B. Chakravarty, Medical Journal Armed Forces India, 1-4 (2014)
10. F. Rangkuti, Manajement Persediaan. Jakarta: PT Raja Grafindo Persada (1996)

11. R. Pressman, Software Engineering: A Practitioner is Approach. New York: McGraw- Hill (2001) 